\title{
LIFE CYCLE ASSESSMENT OF BEVERAGE PACKAGING
}

\author{
Alice Brock and lan Williams * \\ University of Southampton, Faculty of Engineering and the Environment, University Rd, Highfield, Southampton SO17 1BJ, United \\ Kingdom
}

Article Info:
Received:
14 November 2019
Revised:
28 April 2020
Accepted:
25 May 2020
Available online:
5 October 2020
Keywords:
Beverage packaging
Waste management
Life cycle assessment
Plastic
Aluminium
Tetra-pak

Article Info:

Received:

Revised:

28 April 2020

Available online:

5 October 2020

\section{ABSTRACT}

Global plastic production has been increasing annually since World War II and is currently at least 380 million tonnes. Plastic drinks packaging is ubiquitous; over 13 billion plastic bottles are used per year in the United Kingdom alone. Global concern about pollution from plastics in the seas and the environmental costs of plastics manufacture is rising. This study aimed to: i) review the costs, benefits, advantages and disadvantages of plastics as packaging materials and ii) use life cycle assessment to determine if there is less environmentally impactful beverage packaging than plastic bottles. As different beverages have different packaging needs, three categories were used: commonly used containers for milk, fruit juice and pressurised 'fizzy' drinks. The packaging types included in the assessment were glass bottles, aluminium cans, milk cartons, Tetra Pak, polyethylene terephthalate (PET) bottles and high-density polythene (HDPE) bottles. The ISO 14040:2006 and ISO 14044:2006 standards for life cycle assessment formed the basis of the methodology. The open source software openLCA was used to conduct the life cycle assessments. Data was assembled from free LCA databases such as the European reference Life Cycle Database of the Joint Research Center (ELCD), existing life cycle assessments, scientific reports and peer reviewed literature. The functional unit was set at a container that held one litre of fluid. The results found that in each category there was a less impactful beverage packaging than plastic bottles. In the Pressurised Beverage Category, it was found that $100 \%$ recycled aluminium cans would be the least impactful option, in the Fruit Juice Beverage Category it was found that Tetra Pak would be the least impactful option and in the Milk Beverage Category it was found milk cartons would be the least impactful option.

\section{INTRODUCTION}

Beverage containers have been in existence nearly as long as civilisation. Needing something in which to hold and store drinks, humans used a wide range of containers such as animal skins, stone, earthenware and glass. These containers were usually hardwearing and used repeatedly. In the modern era, many drinks containers are made of plastic and have become single use; used once then disposed of. This is due to changes in lifestyle; individuals no longer make much of their own food or buy products such as milk from local sources. The rise of convenience food and mass production has changed how beverages are purchased, stored and consumed. A reduction in food prices means that consumers are buying more beverage packaging because they are, in general, able to afford more food (Andreyeva et al., 2010; Epstein et al., 2012).

Plastics have become a fundamental global feature of everyday life. Plastic is an umbrella term for items manufactured with any synthetic or semi-synthetic organic polymers. Plastic may be shaped when soft and then hardened to retain a given shape. A polymer is a chain in which each link is the "mer," or monomer (single unit). The chain is manufactured by joining, or polymerizing, at least 1,000 links together. The most produced polymers are, in descending order: polyethylenes (low and high density) (PE), polypropylene (excluding fibres) (PP), fibres of acrylic, polyamide and polyester, then polyvinyl chloride (PVC), polyethylene terephthalate (PET) and polystyrene (PS) (Geyer et al. 2017).

Plastics have a number of benefits as a packaging material for beverages as they are light, durable and cheap to produce, able to withstand pressure and can contain many different fluids safely. Nevertheless, plastics have limited recyclability; they are made of polymer chains that shorten each time they are recycled and thus usually 'downcycled' into a lower quality product rather than back into packaging (La Mantia, 2004). Methods such as life cycle assessment (LCA) enable an evaluation of the true costs and benefits of plastic packaging materials. 
Plastic bottles are the world's most common beverage packaging. In the UK; in the year 2016, >13 billion plastic bottles were produced, with only 7.5 billion of those going for recycling (Environmental Audit Committee, 2017). The most common types of plastic bottles for beverages are made from PET or HDPE. Both plastics have been highlighted as a priority pollution problem (Environmental Audit Committee, 2017). Indeed, a ban on plastic bottles for beverages has been widely touted for both environmental and public health reasons (see e.g. Thompson et al, 2007). However, a ban on plastic beverage bottles would remove a practical option for water storage and dissemination during times when municipal tap water supplies are contaminated. Plastic bottles are versatile (can keep liquids hot or cold), relatively inexpensive, and can keep beverages healthy, safe, and convenient. In developing countries with poor infrastructure, bottled water offers a partial solution to unsafe drinking water. Clearly, there are well-developed arguments on both sides

The abundance of plastics, particularly disposable items, has generated a global public outcry over plastic pollution. Items such as plastic straws are being banned (The Ellen McArthur Foundation, 2016). There is a focus on plastic bottles as a waste product or plastics as a pollutant but the entire life cycle of a plastic bottle must be considered to understand its full environmental impacts. Plastic manufacture relies on the extraction of raw materials such as crude oil; this has environmental impacts which are not always noted with the same attention as, for example, marine plastic pollution (O'Rourke and Connolly, 2003). Adverse impacts can include; ozone depletion, petroleum hydrocarbon emissions to the atmosphere and a high generation of solid wastes (O'Rourke and Connolly, 2003). These impacts are purely for the extraction of the raw material, they do not account for the energy needs and emissions generated from manufacture or additional processes. The whole life cycle must be assessed to address all the impacts of plastic.

To minimise the impacts plastics have on the environment, avoidance or minimisation of use is key. However, vital items must be manufactured from plastics, such as personal protective equipment - so important during the Covid19 pandemic - in the health sector. Some products such as beverage packaging have a long history of manufacture from a variety of materials. Replacing plastics with a less impactful packaging type may help mitigate the many impacts of plastics.

Plastics are used for packaging various beverages. According to the UK Department for Environment, Food \& Rural Affairs' (DEFRA) Family Food Statistics 2016/2017, the amount of milk purchased per person is comparable to the amount of soft drinks purchased per person. To understand the impacts of plastics used to package beverages, different beverages with different packaging needs should be examined.

Each type of packaging has different requirements, fizzy drinks require packaging that can be pressurised, milk packaging needs to aid refrigeration and fruit juices are often unrefrigerated so have specific hygiene needs. Knowing which packaging has the least impacts for each type of beverage could aid consumers, lawmakers, pressure groups and businesses to understand the true impacts of beverage packaging in relation to each.

\section{LIFE CYCLE ASSESSMENT OF BEVERAGE PACKAGING}

\subsection{Previous studies}

LCA is a suitable tool to compare different types of packaging that serve the same purpose as it compares the products assessed against only each other. LCA is based on product system results in relation to each other rather than their impacts overall; it can only show if something is 'better' or 'worse' than another. LCA is guided by two International Organization for Standardization (ISO) standards, ISO 14044:2006 and ISO 14040:2006, and for an LCA to be deemed valid by other practitioners, it should adhere to these standards (Bjørn et al., 2018c).

LCA is often considered when the sustainability of a product or process or measurement of how 'environmentally friendly' something is needed. A number of studies have used LCA to review the environmental impacts of drinks packaging, with some focusing just on plastics packaging, or on specific types of beverages such as carbonated drinks or milk (Amienyo et al., 2013; Romero-Hernández et al., 2009). Many LCAs have been conducted on beverage packaging, some by companies on behalf of beverage packaging producers and others by academics. Almost all follow the ISO standards for LCA and many assess glass and PET bottles due to their use across different beverages.

The majority of LCAs that have assessed beverage packaging concluded that glass is the most impactful beverage packaging regardless of the other packaging types involved (Amienyo et al., 2013; Franklin Associates, 2009; Jelse et al., 2009; Meyhoff Fry et al., 2010; Saleh, 2016). Amienyo et al, (2013), noted that glass had the highest global warming potential (GWP) compared with aluminium cans and PET bottles and concluded that the PET bottle was the least impactful of the three. PET and HDPE bottles' assessed impacts vary across recent LCAs, however they are consistently presented as less impactful than glass and more impactful than composite packaging such as milk cartons (Franklin Associates, 2009; Jelse et al., 2009; Meyhoff Fry et al., 2010).

A report by Franklin Associates (2009) concluded that aluminium cans are more impactful than PET bottles as they have higher energy demands, higher solid waste generation and greenhouse gas emissions. However, the report also noted that aluminium can manufacture uses less fossil fuels than PET bottle manufacture due to the widespread use of hydropower in primary aluminium smelters (Franklin Associates, 2009). This highlights the importance of correctly allocating energy sources within LCAs e.g. the work of Saleh (2016), based in Palestine, reported drastically different values than the Franklin Associates (2009) study based in America. Data must be suitable for the country of study.

Meyhoff et al, (2010) and Jelse et al, (2009) found product systems with plastic elements were the most impactful in the product systems compared and both advocated 
lessening plastic content. Jelse et al, (2009) found that Tetra Pak containers with plastic caps had $\sim 30 \%$ higher GWP than other Tetra Pak product systems, indicating that even a comparatively small increase in plastic content can cause a considerable increase in impacts (Jelse et al., 2009). Both these studies included plastic bottles and products that contained some element of plastic, therefore were comparing similar products, and demonstrating how ubiquitous plastics are in beverage packaging.

Amienyo et al, (2013) compared PET packaging to packaging without plastic elements and found it less impactful, within the system boundaries of the study, than the glass bottles and aluminium cans in many categories. Different levels of reuse and recycling were included as PET plastics have a limited recyclability whereas both glass and aluminium can be recycled indefinitely (Amienyo et al., 2013). The study - unsurprisingly - found that improving recycling and reuse of all packaging types would lessen their impacts. Accorsi et al's (2015) conclusions seem different from that of Ameinyo et al, (2013), classing glass bottles for extra virgin olive oil (EVOO) as less impactful than PET bottles, though this was under the assumption that the glass was recycled at a higher rate and with differing transportation assessed.

Glass generally has the highest impacts out of beverage packaging options, followed by plastics and aluminium cans that are found to be more impactful than composite packaging. Many current LCAs only focus on one beverage type, or compare packaging without being concerned with beverage type (Cleary, 2013; Saleh, 2016).

Existing LCAs for beverage packaging are not without flaws. An LCA is a complex undertaking and at every stage, many decisions are made in terms of allocation, data quality, what will and will not be included in the scope of the assessment and the impact categories that will be assessed. Quality of data is essential in creating a relevant, reliable and authentic LCA. The information that goes into the life cycle inventory may not be perfect; some data may be hard to find or measure or just be too ambiguous to include (Bjørn et al., 2018a). As each LCA has a different scope and boundaries, there will be different data requirements and different conclusions drawn. Several LCAs include transport as a key variable, modelling different product systems with different transportation distances as part of the comparison (Amienyo et al., 2013; Fachverband and Kartonverpackungen, 2007; Jelse et al., 2009). For these studies, assumed distances are applied and modelled, for other studies transportation has been decided upon by experts or given an average value (Meyhoff Fry et al., 2010). Meyhoff Fry et al, (2010) did not provide transportation distance for all product systems causing an imbalance when it comes to accuracy within the LCA. Transport can have high impact contributions due to fuel usage and emissions so inaccuracy could alter the results significantly. In some LCAs, transport is scoped out of the system boundary entirely due to the difficulty of accurately quantifying the distances the packaging would have to travel (Bjørn et al., 2018b; Curran, 2017a). For such reasons, this study will not include transportation.

It is clearly important to identify a relevant functional unit for beverage packaging due to the dimensions of each packaging type, as they are hollow vessels. A factor indicated by Cleary (2013) was that the mass of the container per amount of beverage contained is important, hypothetically 1 kilogram of PET may have more impacts than a kilogram of glass but the amount of PET to hold 1 litre of a beverage is far below the amount of glass needed for the same purpose (Cleary, 2013). Therefore, this study will use a functional unit based on the volume of beverage contained, not packaging weight.

Weighting, alongside normalisation, is a controversial step used in some LCAs. It involves assigning certain impacts a higher value than others, for example human health may be considered to have a greater weight than marine ecotoxicty in certain weighting sets (Bare et al., 2008). Saleh (2016) created a weighting set using a survey of experts to assign values to each category. There are standard weighting sets produced by different organisations, but some LCAs only briefly mention they have used weighting and do not always explain the weight given to impact categories, e.g. the study by Cleary (2013).

As results are only for a specific functional unit, a LCA cannot show any potential runaway processes that might occur when certain levels of outputs are reached (Rosenbaum et al., 2018). LCA data comes from different geographical areas - even within relatively small countries like the UK - and timeframes and cannot account for any unique characteristics of specific areas, such as existing contamination, temperature or other local emissions or outputs from other activities and products that might interact with those from the product system (Rosenbaum, 2017).

\subsection{Purpose of study}

LCAs often compare a few packaging types without specific concerns for the beverage the packaging will contain or study a variety of packaging types, particularly many variations of certain products, such as Tetra Pak variants. This study will consider three categories of beverage containers; pressurised drinks, unrefrigerated fruit juice and fresh milk containers. Two hypothetical $100 \%$ recycled packaging types will be included for glass and aluminium to indicate their near infinite recyclability only, as packaging made of $100 \%$ recycled materials are not common these hypothetical containers are purely for comparative purposes. Plastics' overall costs and benefits as beverage packaging are critically evaluated for pressurised beverages, fruit juice and milk.

The aims of the study were to: i) critically evaluate and review the costs, benefits, advantages and disadvantages of plastics as a beverage packaging material; and ii) identify, using life cycle assessment, if there are suitable replacements for beverage packaging constructed from plastics which have lower environmental impacts.

\section{METHODS}

Each beverage packaging category assessed had at least one form of plastic packaging. The software package OpenLCA (http://www.openlca.org/) was utilised as it is a free, widely-used open source program that is compatible with numerous impact methods. Data was collected 
from reliable sources such as existing LCA databases, peer-reviewed literature and scientific reports, and collated in a Microsoft Excel spreadsheet. The results of the LCA were compared within each drinks category to identify if there is a packaging type that has fewer environmental impacts than plastics. The study used ISO 14044:2006 and IS014040:2006 standards as a framework. The data used, and data sources can be found in Appendix 1.All impacts were equally weighted.

\subsection{Life cycle assessment stages}

The four stages for LCA are outlined below; whilst they are separate stages many inform the others and there can be adjustment throughout the process (Mathews et al, 2018).

Goal and Scope Definition: ISO 14044:2006 states that the goal must be clearly defined with four statements needed in key areas. 1) Intended application; 2) Reason for carrying out study; 3) Audience; 4) If the results are used in publicly released comparative assertions. The scope consists of several qualitative and quantitative pieces of information that define what is and is not included in the study, the parameters of the study and which product systems were studied. Information such as the functional unit is decided upon in this stage.

Inventory Analysis: Collection and documentation of data gathered in accordance to the needs of the goal and scope. Data is collected, validated, allocated to its associated processes and some data often has to be converted to the functional unit, it was aggregated for the analysis, in this study it was stored in Microsoft Excel. For the inventory analysis product systems were collated within openLCA, a product system includes all the gathered data involved in the product's life cycle organised in such a way that it can then be used in the LCA.

A product system includes the processes for the inputs and outputs of the system, for example for a plastic bottle petroleum must be extracted, so the process to extract the petroleum would be included in the product system with the petroleum as the 'flow' into the next process.

Impact Assessment: This is the stage where the study moved beyond individual flows and processes and assessed that the impacts of the product system were in accordance to the goal and scope. Impact categories were chosen that were relevant to the goal and scope of the study and the choices must be justified. IS014040:2006 states that these impact categories must be listed explicitly in the study. Using openLCA the life cycle impact assessments were generated for each category, this stage was largely automated and involved ensuring that all data was correct, impact categories were correctly chosen and that there were no technological errors (Rosenbaum et al., 2018). It was in this stage that data was assessed for the impacts of each product system for each impact category.

It is important to understand through this stage and the interpretation stage that what the life cycle impact analysis shows is potential or theoretical impacts. To meet the ISO Standards for LCAs there were three mandatory steps for the life cycle impact assessment stage:

i. Selection of impact categories, indicators and characterisation modules, this step is completed by choosing from existing LCIA methods.

ii. Classification of the $\mathrm{LCl}$ results, assigning them to impact categories based on what their known impacts are, this is typically done by the software automatically.

iii. Characterisation of the results, the software will quantify how much each of the inventory flows are contributing to the impact categories.

Interpretation: The ISO standard gives less in terms of guidance on this stage, but the aim of the interpretation stage is to examine the results to be able to report any findings, recommendations or conclusions (see Discussion). The optional weighting and normalisation step of LCA was not preformed. Weighting is controversial because unless the LCA has a specific purpose, such as examining impacts on human health, it can be difficult to justify what weight impacts could have in relation to each other. This study will not use weighting, mainly as it limits a study's ability to be used as a comparative piece of work and justification for specific weighting is highly subjective (Bettens and Bagard, 2016; Jelse et al., 2009).

\subsection{Data}

Data was obtained from a range of authoritative sources, as shown in Appendix 1. Many datasets were examined but only the most relevant and robust were selected. Data was gathered or adapted for the functional unit. The weight of each packaging container was estimated by calculating an average of the weights of 10 different examples of each packaging type. For the aluminium can, ten $500 \mathrm{ml}$ cans were weighed and a theoretical litre can was modelled. When data from different sources or datasets was used, it was carefully processed in order to avoid double counting of any materials, impacts or outputs in the product system. As datasets for processes in glass manufacture were not available, data from many sources had to be adapted to model these processes.

Data was assembled for three categories of beverage packaging each containing a different liquid: non-refrigerated fruit juice, fresh milk and pressurised drinks such as cola. Each of these three categories included the most commonly used plastic packaging used for the beverage as a baseline as well as other commonly used packaging types (Table 1). All categories included glass bottles so a

TABLE 1: Beverage packaging categories and types of packaging assessed.

\begin{tabular}{|c|c|c|c|c|c|}
\hline Category & Plastic packaging & Other packaging & Other packaging & Hypothetical recycled packaging & Hypothetical recycled packaging \\
\hline Fruit Juice & PET Bottle & Tetra Pak & Glass Bottle & $100 \%$ Recycled Glass & \\
\hline Milk & HDPE Bottle & Milk Carton & Glass Bottle & $100 \%$ Recycled Glass & \\
\hline Pressurised & PET Bottle & Aluminium Can & Glass Bottle & $100 \%$ Recycled Glass & $100 \%$ Recycled Aluminium Can \\
\hline
\end{tabular}


TABLE 2: Processes scoped in and scoped out of product systems.

\begin{tabular}{l|l} 
Scoped In & Scoped Out \\
\hline Extraction of virgin materials & $\begin{array}{l}\text { Transport }- \text { for all stages of production including virgin material extraction } \\
\text { and end of life treatment. }\end{array}$ \\
\hline $\begin{array}{ll}\text { Manufacture of packaging } \\
\text { End of life treatment -including landfill, burning and recycling for each pro- } \\
\text { duct according to UK rates of disposal }\end{array}$ & \begin{tabular}{l} 
Beverage manufacture \\
\hline
\end{tabular} \\
\hline
\end{tabular}

hypothetical $100 \%$ recycled glass bottle was included to demonstrate the ability of glass to be constantly recycled without degrading as plastic does. The same was completed for hypothetical $100 \%$ recycled aluminium cans in the Pressurised Beverage Category.

\subsection{Functional unit, goal and scope}

The functional unit was the packaging required to hold 1 litre of a specific beverage. This was modelled as one single container for each functional unit, so the aluminium can was modelled as a hypothetical can that could hold 1 litre. This is to keep consistency of scale across the LCA; if the PET bottle unit used was a 1 litre bottle against ten 100 $\mathrm{ml}$ glass bottles the glass would hold the same amount of fluid but the weight of glass would be far greater than for a single 1 litre container. In accordance with the requirements to present the scope of the study Table 2 shows the scoped in and out processes for product systems.

Cut-offs are points beyond which parts of the product system are considered too small or insignificant to be counted. In some LCAs this is when the material in question constitutes less than $5 \%$ of the finished product and in others it is 1\% (Curran, 2017a). For other parts of the product system it might relate to how much energy they require or contribute; below a certain threshold they can be considered irrelevant to the goal and scope of the specific study (Curran, 2017a). For this study, any process that contributes less than $1 \%$ of material or energy to the product was not included in the scope of this study.
Although the methodology utilised may be universally applied, the scope of this study relates to UK practices and uses relevant data. We used data from 2010 onwards unless no reliable and robust data was available and older data was necessarily adapted. Two different product system 'types' were studied due to the inclusion of the two hypothetical $100 \%$ recycled product systems. Figure 1 shows the product system and scoped in and scoped out processes for the beverage packaging that is not $100 \%$ recycled. Figure 2 shows the product system and scoped in and scoped out processes for the $100 \%$ recycled beverage packaging product systems.

\subsection{Allocation and impact categories}

Allocation is the process by which each process and output is associated with the correct product, flow and the like. Correct allocation was achieved by consulting the literature closely for each product and ensuring that when data was taken from different sources there was no double counting. There are many different impact categories available; each uses indicators allowing a prediction of the impacts of the product system. The categories for this study are shown in Table 3.

\subsection{Assumptions and limitations}

Note that some data had to be adapted using reasonable assumptions made, particularly where complete process datasets could not be found or datasets from other countries had to be adapted with UK energy usage
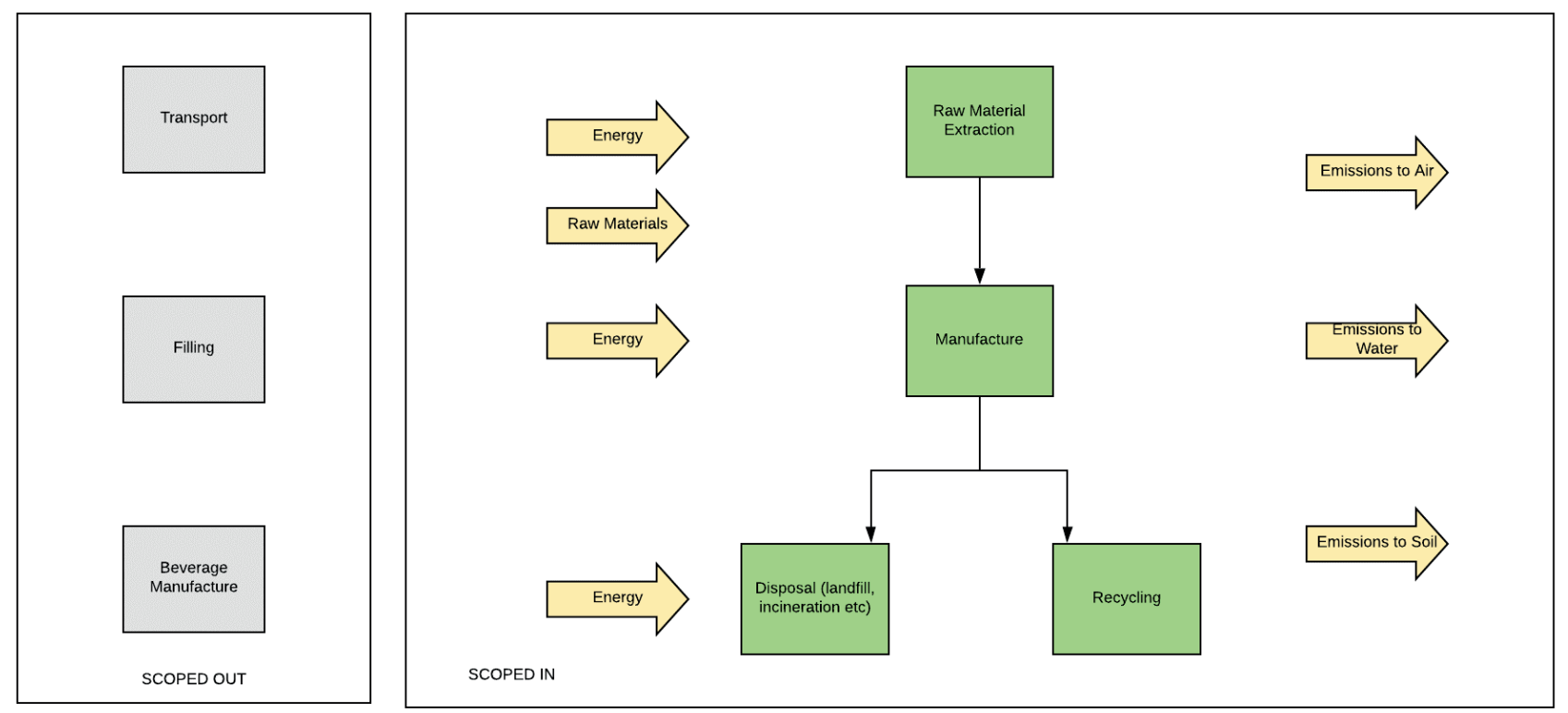

FIGURE 1: Product system and scoped out processes for beverage packaging made from virgin materials. 

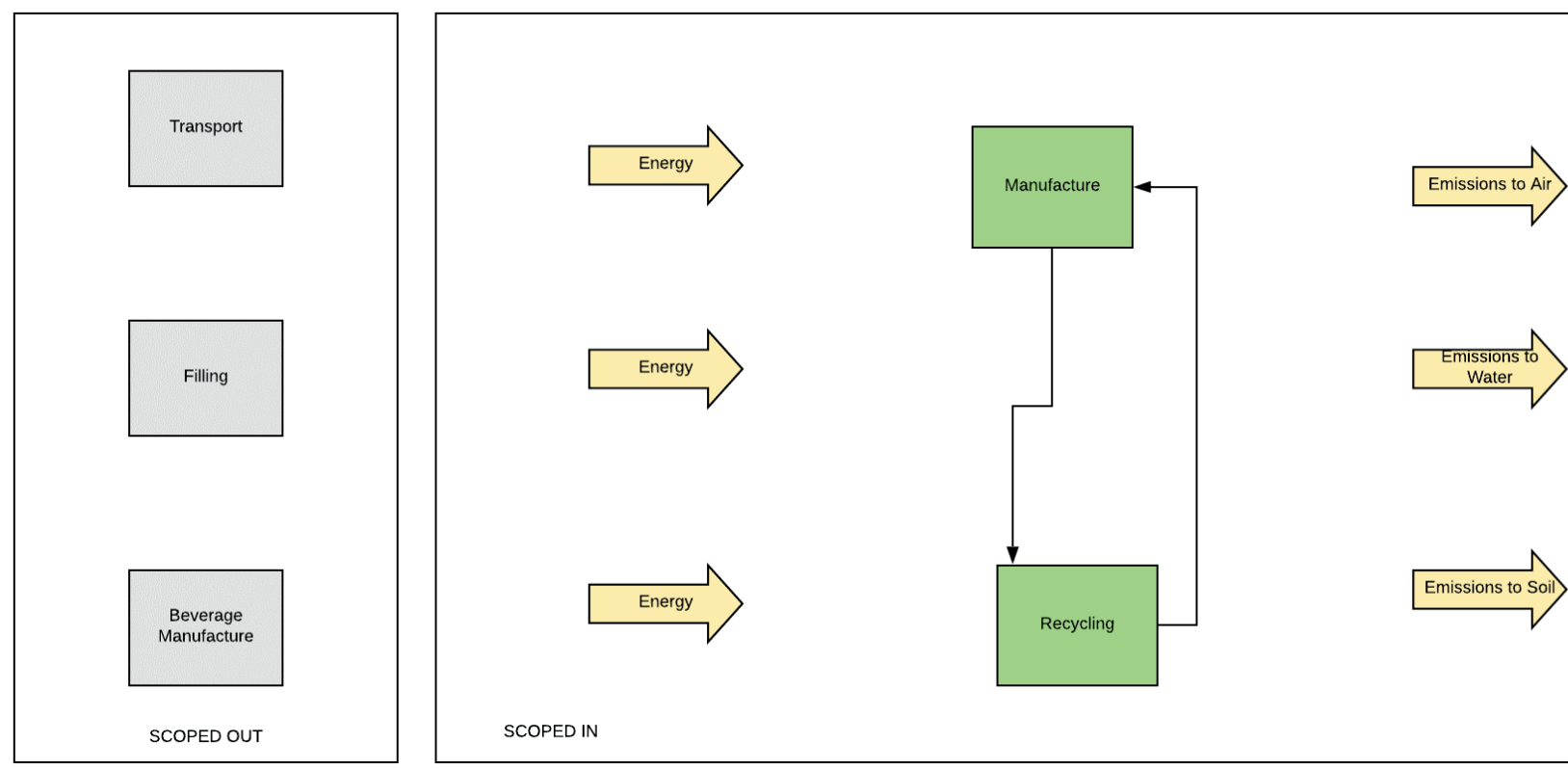

FIGURE 2: Hypothetical product system and scoped out processes for beverage packaging made from $100 \%$ recycled materials.

or flows. Assumptions had to be made for the Tetra Pak product system as accurate manufacturer's data could not found so data for milk carton production was adapted.

\section{RESULTS}

\subsection{Introduction}

The results of all three categories showed clear differences in each beverage packaging's impact within each CML impact category. All three drinks categories had glass bottles as one of the packaging types and in all three the virgin glass bottle had the highest impacts in most CML categories, with PET bottles showing maximum indicators in the two beverage categories in which it was present.

When showing the data in graphical form, the maximum indicator has a value of $100 \%$ and each other prod- uct's indicator is shown relative to the maximum indicator. To ascertain which beverage packaging types in each beverage category were the most impactful, each beverage packaging was ranked for each impact category, with the initial table showing the ranks and an additional table showing the collated results. The lowest scoring beverage packaging is the most impactful in that category. Whilst it is often easy to see from the maximum indicators that are the most impactful in a category, how the other categories relate to each other in a cumulative fashion can be harder to define.

Using these ranked scores, the most impactful and least impactful beverage packaging types overall for each category were quantified. These scores were used to identify which packaging types were most impactful across categories.

TABLE 3: CML (Institute of Environmental Sciences, Leiden University) impact categories and their descriptions.

\begin{tabular}{|c|c|}
\hline CML Impact Category & Description of Impact Category \\
\hline Acidification Potential - Average Europe & The potential of the product system to cause acidification \\
\hline Climate Change - GWP 100 & $\begin{array}{l}\text { The potential of the product system to impact climate change through 'global warming } \\
\text { potential' }\end{array}$ \\
\hline Depletion of Abiotic Resources - elements, ultimate reserves & $\begin{array}{l}\text { The loss of resources due to the product system such as chemical elements and overall } \\
\text { reserves of resources }\end{array}$ \\
\hline Depletion of Abiotic Resources - fossil fuels & The loss of fossil fuel resources due to the product system \\
\hline Eutrophication - generic & The potential of the product system to cause eutrophication in all waters \\
\hline Freshwater Aquatic Ecotoxicity & The potential of the product system to have toxic outputs into freshwater systems \\
\hline Human Toxicity & The potential of the product system to have toxic impacts on human health \\
\hline Ozone Layer Depletion & The potential of the product system to deplete the ozone layer in its current state \\
\hline Photochemical Oxidisation & $\begin{array}{l}\text { The potential of the product system to generate NOx and cause 'summer smog' due to } \\
\text { air pollution }\end{array}$ \\
\hline Terrestrial Ecotoxicity & The product system's potential to have toxic impacts on terrestrial environments \\
\hline Marine Aquatic Ecotoxicity & The product system's potential to have toxic impacts on marine environments \\
\hline
\end{tabular}




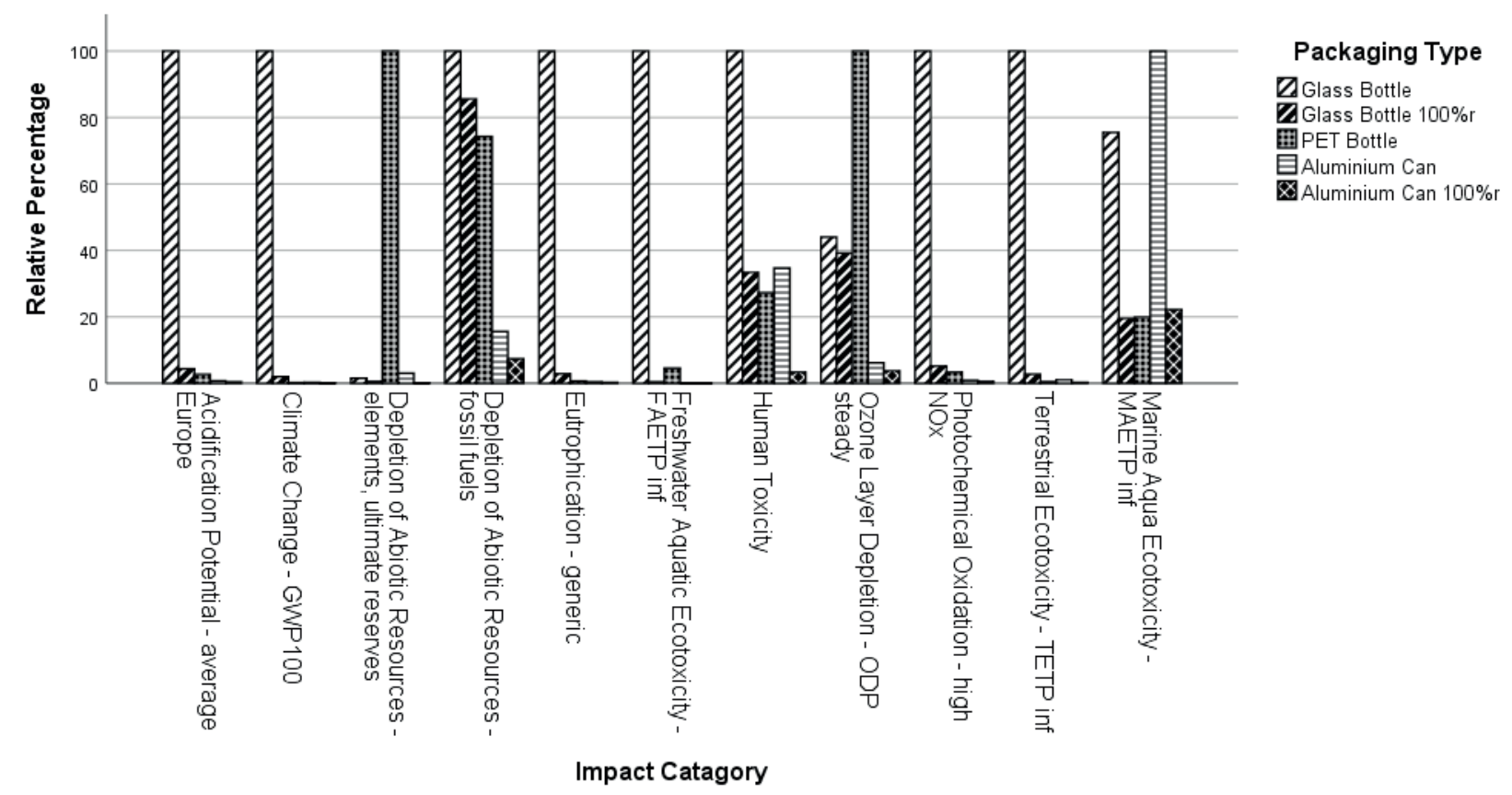

FIGURE 3: Relative results from pressurised beverage packaging category using CML impact methods. Product with the maximum indicator is set to $100 \%$ and other variants displayed in relation to this result indicating differences from maximum impact indicator.

\subsection{Pressurised Beverage Packaging Life Cycle As- sessment}

The Pressurised Beverage Packaging Category LCA had the highest number of product systems assessed, including the PET plastic bottle (entirely plastic packaging) and a hypothetical $100 \%$ recycled glass bottle and a hypothetical $100 \%$ recycled aluminium can. Results from the life cycle assessment are presented in Figure 3.

The recycled containers were assessed to have lower impacts overall than their counterparts made of virgin materials. The $100 \%$ recycled aluminium had the lowest impacts overall in this category with the lowest impacts in all categories except 'Marine Aquatic Ecotoxicity' (lower than its virgin counterpart). The beverage packaging type with the most maximum indicators was the virgin glass bottle, the maximum in eight of the twelve categories.

The PET bottle scored the maximum indicator for two categories; 'Depletion of Abiotic Resources - elements, ultimate reserves' and 'Ozone Layer Depletion'. The virgin aluminium can was the maximum indicator for the 'Marine Aquatic Ecotoxicity' category.

Within the Pressurised Beverage Category (ranks shown in Table 4, combined results shown in Table 5), the glass bottle was the highest ranked overall for environmental impacts across all impact categories with the $100 \%$ recycled glass bottle second. The $100 \%$ recycled aluminium can is the lowest ranked gaining the lowest score of 5 in all categories bar one, Marine Aquatic Toxicity, where it

TABLE 4: Ranks for each beverage packaging in the Pressurised Beverage Packaging Category across all eleven CML impact categories; 1 is the highest rank for the most impactful packaging, 5 is the lowest for the least impactful..

\begin{tabular}{|c|c|c|c|c|c|c|c|c|c|c|c|}
\hline $\begin{array}{l}\text { Beverage } \\
\text { Packaging } \\
\text { Type }\end{array}$ & 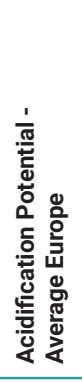 & 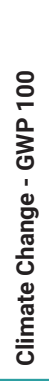 & 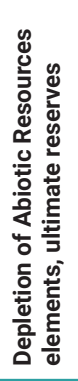 & 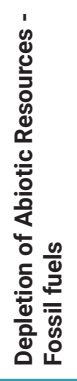 & 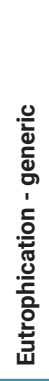 & 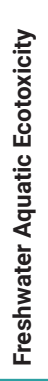 & 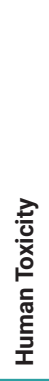 & 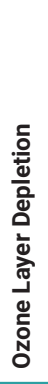 & 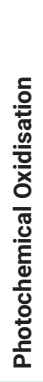 & 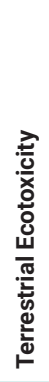 & 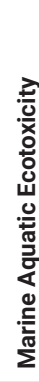 \\
\hline Glass Bottle & 1 & 1 & 3 & 1 & 1 & 1 & 1 & 2 & 1 & 1 & 2 \\
\hline Glass Bottle $100 \%$ R & 2 & 2 & 4 & 2 & 2 & 3 & 3 & 3 & 2 & 2 & 5 \\
\hline PET Bottle & 3 & 3 & 1 & 3 & 3 & 2 & 4 & 1 & 3 & 4 & 4 \\
\hline Aluminium Can & 4 & 4 & 2 & 4 & 4 & 4 & 2 & 4 & 4 & 3 & 1 \\
\hline Aluminium Can $100 \%$ R & 5 & 5 & 5 & 5 & 5 & 5 & 5 & 5 & 5 & 5 & 3 \\
\hline
\end{tabular}


TABLE 5: Collated rank scores for each beverage packaging type in the Pressurised Beverage Category.

\begin{tabular}{l|c} 
Beverage Packaging Type & $\begin{array}{c}\text { Ranked Score (lowest value is } \\
\text { most impactful) }\end{array}$ \\
\hline Glass Bottle & 15 \\
\hdashline Glass Bottle $100 \% \mathrm{R}$ & 29 \\
\hline PET Bottle & 32 \\
\hline Aluminium Can & 35 \\
\hline Aluminium Can $100 \% \mathrm{R}$ & 53 \\
\hline
\end{tabular}

scored 3. Notably this is the impact category in which the virgin aluminium was identified as the most impactful beverage packaging. Both categories of aluminium cans were less impactful overall than the PET plastic bottle according to the ranked scores. The recycled versions of the glass bottle and the aluminium can both came second to their virgin counterpart.

\subsection{Fruit Juice Beverage Packaging Life Cycle As- sessment}

The Fruit Juice Beverage Packaging Category was the only one to assess the impacts of Tetra Pak. Results from the LCA are shown in Figure 4. This category shows similar results to the Pressurised Beverage Category, with glass being assessed to have the highest impacts overall. The PET bottle has the highest impacts in the same two categories as in the 'Pressurised Beverage' category; 'Depletion of Abiotic Resources - elements, ultimate reserves' and 'Ozone Layer Depletion'. The key difference is the inclusion of the Tetra Pak container, which shows comparatively very low impacts compared to the other product systems even with no recycled content, the only categories where Tetra Pak has noticeable impacts are both the marine and freshwater toxicity and fossil fuel depletion.
Within the fruit juice beverage category, ranks shown in Table 6, the combined results shown in Table 7, the glass bottle was the highest ranked overall for environmental impacts across all impact categories with the $100 \%$ recycled glass bottle the second most impactful. The Tetra Pak carton is the lowest ranked gaining the lowest score of 4 in all but two categories, scoring 3 in Depletion of 'Abiotic Resources elements, ultimate reserves' and scoring 2 in 'Freshwater Aquatic Ecotoxicity'. The PET bottle was the third most impactful of the four ranked beverage packag-

TABLE 6: Ranks for each beverage packaging in the fruit juice beverage packaging category across all eleven CML impact categories; 1 is the highest rank for the most impactful packaging, 5 is the lowest for the least impactful.

\begin{tabular}{|c|c|c|c|c|c|c|c|c|c|c|c|}
\hline $\begin{array}{l}\text { Beverage } \\
\text { Packaging } \\
\text { Type }\end{array}$ & 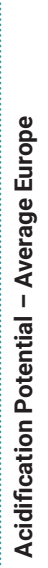 & 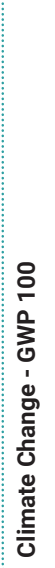 & 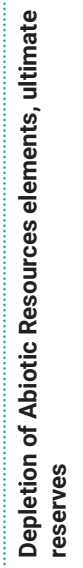 & 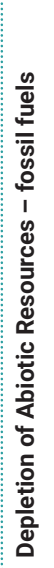 & 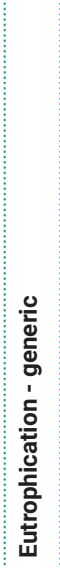 & 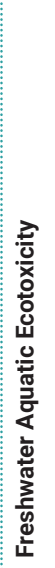 & 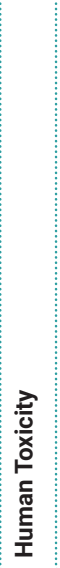 & 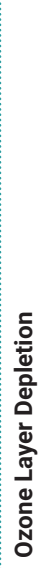 & 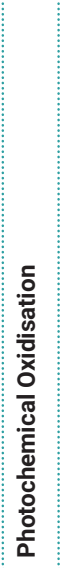 & 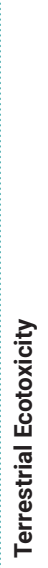 & 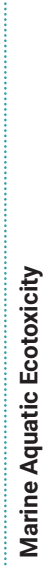 \\
\hline Glass Bottle & 1 & 1 & 2 & 1 & 1 & 1 & 1 & 2 & 1 & 1 & 1 \\
\hline $\begin{array}{l}\text { Glass Bottle } \\
100 \% \text { R }\end{array}$ & 2 & 2 & 3 & 2 & 2 & 4 & 2 & 3 & 2 & 2 & 3 \\
\hline PET Bottle & 3 & 3 & 1 & 3 & 3 & 3 & 3 & 1 & 3 & 3 & 2 \\
\hline Tetra Pak & 4 & 4 & 3 & 4 & 4 & 2 & 4 & 4 & 4 & 4 & 4 \\
\hline
\end{tabular}

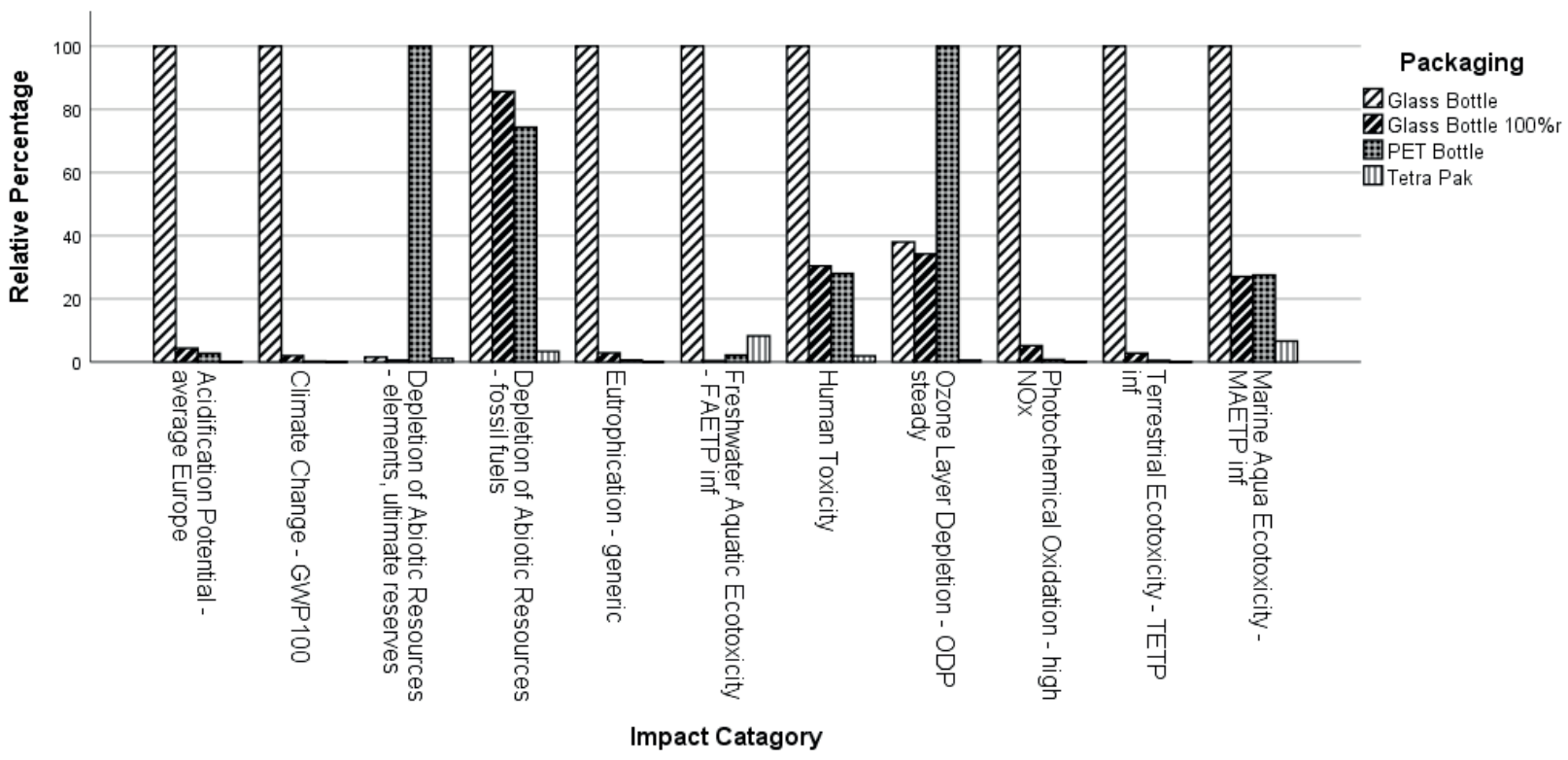

FIGURE 4: Relative results from Fruit Juice Packaging category CML impact methods. Maximum indicator is set to $100 \%$ and other variants displayed in relation to this result indicating differences from maximum impact indicator. 
TABLE 7: Collated rank scores for each beverage packaging type in the Fruit Juice Beverage Category.

\begin{tabular}{l|c} 
Beverage Packaging Type & $\begin{array}{c}\text { Ranked Score (lowest value is } \\
\text { most impactful) }\end{array}$ \\
\hline Glass Bottle & 13 \\
\hline Glass Bottle 100\%R & 27 \\
\hline PET Bottle & 30 \\
\hline Tetra Pak & 41 \\
\hline
\end{tabular}

ing types in this category, and did score the highest ranks in two categories 'Abiotic Resources elements, ultimate reserves' and 'Ozone Layer Depletion' the same impact categories the PET bottle gained the highest rank for in the pressurised beverage packaging LCA rankings.

\subsection{Milk Beverage Packaging Life Cycle Assessment}

The milk beverage packaging category LCA was the only one that included the HDPE plastic bottle as the baseline plastic. It also was the only LCA to include the milk carton and HDPE plastic bottle; this LCA had the hypothetical $100 \%$ recycled glass bottle as a recycled option (Figure. 5). Both glass bottles were the most and second most impactful packaging type in all categories in this LCA, the HDPE bottle was the third most impactful packaging type in all the impact categories. Unlike the PET bottle in the other beverage categories the HDPE bottle did not have a higher impact in any impact category than the glass bottles. The milk carton has low overall impacts in all categories.

Within the Milk Beverage Category, ranks shown in Table 8, the combined results shown in Table 9, the glass bottle was the highest ranked overall for environmental impacts across all impact categories with the $100 \%$ recycled glass bottle the second most impactful. The milk carton is the lowest ranked in all categories.

The HDPE plastic bottle scored 3 in all categories aside from 'Depletion of Abiotic Resources elements, ultimate reserves' where it scored 4, it did not have the highest impact in any impact category unlike the PET plastic bottle in the two other categories.

\subsection{Most Overall Impactful Beverage Packaging}

Different processes within each product system had the highest contributions to the overall impacts in each

TABLE 8: Ranks for each beverage packing in the Milk Packaging Category across all eleven CML impact categories; 1 is the highest rank for the most impactful packaging, 5 is the lowest for the least impactful.

\begin{tabular}{|c|c|c|c|c|c|c|c|c|c|c|c|}
\hline $\begin{array}{l}\text { Beverage } \\
\text { Packaging } \\
\text { Type }\end{array}$ & 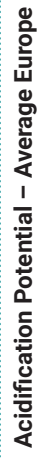 & 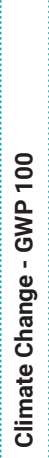 & 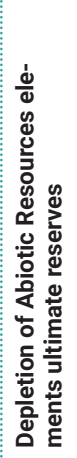 & 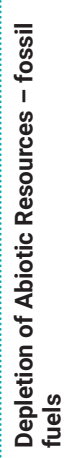 & 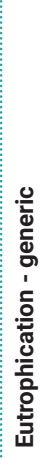 & 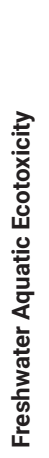 & 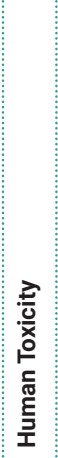 & 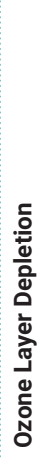 & 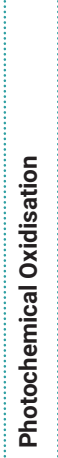 & 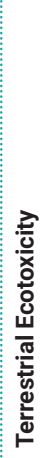 & 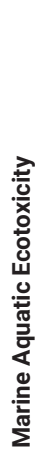 \\
\hline Glass Bottle & 1 & 1 & 1 & 1 & 1 & 1 & 1 & 1 & 1 & 1 & 1 \\
\hline $\begin{array}{l}\text { Glass Bottle } \\
100 \% \text { R }\end{array}$ & 2 & 2 & 2 & 2 & 2 & 4 & 2 & 2 & 2 & 2 & 2 \\
\hline HDPE Bottle & 3 & 3 & 3 & 3 & 3 & 3 & 3 & 3 & 3 & 3 & 3 \\
\hline Milk Carton & 4 & 4 & 4 & 4 & 4 & 2 & 4 & 4 & 4 & 4 & 4 \\
\hline
\end{tabular}

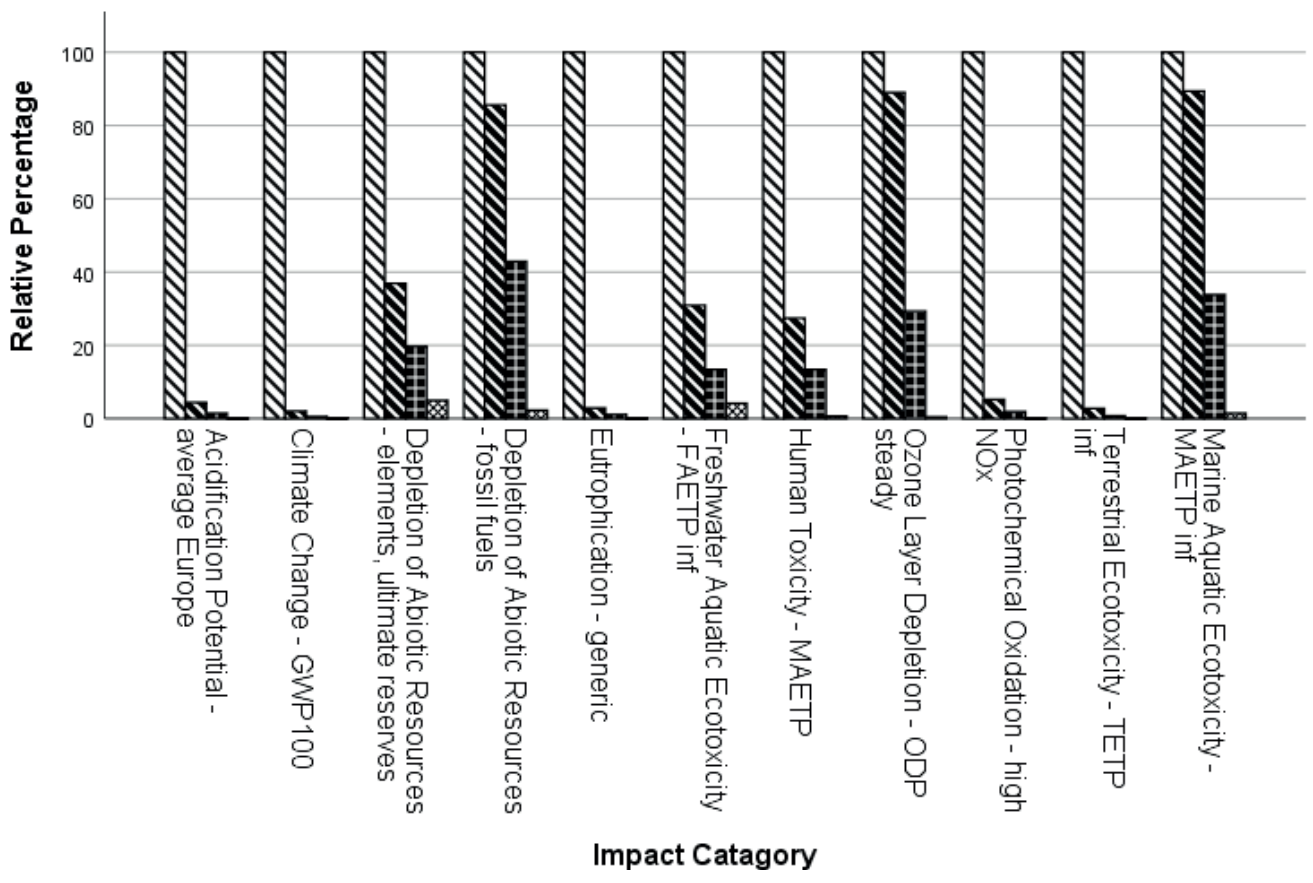

Packaging Type

QGlass Bottle NGlass Bottle $100 \%$ r THDPE Bottle 图Milk Carton

FIGURE 5: Relative results from the Milk Packaging category CML impact methods. Maximum indicator is set to $100 \%$ and other variants displayed in relation to this result indicating differences from maximum impact indicator. 
TABLE 9: Collated rank scores for each beverage packaging type in the Milk Beverage Category.

\begin{tabular}{l|c} 
Beverage Packaging Type & $\begin{array}{c}\text { Ranked Score (lowest value is } \\
\text { most impactful) }\end{array}$ \\
\hline Glass Bottle & 11 \\
\hline Glass Bottle 100\%R & 24 \\
\hline HDPE Bottle & 33 \\
\hline Milk Carton & 42 \\
\hline
\end{tabular}

impact category. Understanding where the impacts come from may demonstrate which processes need improvement or mitigation to minimise impacts. In the ranked scores for all its beverage categories, virgin glass had the highest impacts across all categories, the two plastic bottles both came third in their categories. However, the pressurised beverage packaging category had five packaging types unlike the other two, but in all LCAs plastics ranked below the two glass packaging types and above the other alternatives to plastics.

As glass was overall the most impactful beverage packaging type, understanding exactly where the high impacts are originating could help in minimising them in future packaging. As virgin glass bottles had maximum impacts in all CML categories across the beverage categories all impact categories are included in Table 10.

The virgin glass bottle overall had the highest impacts coming from the glass melting process. Grouped in this process were the extraction of composite materials that made up the glass, the energy to melt the materials and all emissions from the melt. This process releases a high level of gases particularly carbon dioxide (and its equiva- lents) which are the indicators for global warming in the CML impact category 'Climate Change'. In both the beverage categories in which the PET bottle product system was assessed it was the maximum indicator for the same two CML impact categories in Table 11. In both the impact categories for which PET plastic was the maximum indicator in the pressurised beverage and fruit juice categories, the PET granule production was the highest contributor to the impact. PET granule production in these product systems included material extraction.

\subsection{PET and HDPE Plastic Bottle Comparison}

The PET plastic bottle would appear more impactful than the HDPE bottle. However, as life cycle assessment is comparative only to the other product systems in its specific assessment, this could be an incorrect assumption. To assess if there is a significant difference between the two plastic bottles modelled in this study a further LCA was conducted for the two plastic bottles.

The results of the LCA conducted for the HDPE and PET bottles (see Figure 6) indicate that PET plastic bottles have a higher impact overall and in every CML impact category than the HDPE bottle. This demonstrates that not all plastics have the same level of impacts and that even packaging choices within plastic bottle options can vary the potential impact of the packaging.

As PET is the more impactful of the two plastics, and the more abundant, understanding the sources of the impacts within the processes, as with the glass bottles, can help understand which processes may need improving to minimise impacts.

TABLE 10: Highest contributing processes to virgin glass bottles' product system impacts in CML impact categories, Table does not indicate percentage contributed compared to other product systems in categories.

\begin{tabular}{|c|c|c|c|}
\hline Impact Category & Highest Contributor & $\%$ Contributed & Indicator \\
\hline Acidification Potential & Glass Melting & 97.1 & $\mathrm{~kg} \mathrm{SO}_{2}$ eq. \\
\hline Climate Change & Glass Melting & 99.0 & $\mathrm{~kg} \mathrm{CO}_{2}$ eq. \\
\hline $\begin{array}{l}\text { Depletion of Abiotic Resources -ele- } \\
\text { ments, ultimate reserves }\end{array}$ & Waste Incineration & 50.6 & kg antimony eq. \\
\hline Depletion of Resources - fossil fuels & Electricity Demands & 56.8 & MJ \\
\hline Eutrophication & Glass Melting & 98.4 & $\mathrm{~kg} \mathrm{PO}_{4}$ eq. \\
\hline Freshwater Aquatic ecotoxicity & Glass Melting & 99.7 & kg 1,4-dichlorobenzene eq. \\
\hline Human toxicity & Glass Melting & 78.4 & kg 1,4-dichlorobenzene eq. \\
\hline Marine Aquatic ecotoxicity & Glass Melting & 85.6 & kg 1,4-dichlorobenzene eq. \\
\hline Ozone Layer Depletion & Electricity Demands & 59.1 & kg CFC-11 eq. \\
\hline Photochemical oxidation & Glass Melting & 96.6 & kg ethelyne eq. \\
\hline Terrestrial ecotoxicity & Glass Melting & 98.8 & kg 1,4-dichlorobenzene eq. \\
\hline
\end{tabular}

TABLE 11: Highest contributing processes to PET bottles' product system impacts for CML impact categories in which they had highest impacts. Table does not indicate percentage contributed compared to other product systems in categories.

\begin{tabular}{lllll} 
Impact Category & Highest Contributor & $\%$ Contributed & Indicator \\
\hline Depletion of Abiotic Resources -elements, ultimate reserves & PET Granule Production & 99.6 & kg antimony eq. \\
\hdashline Ozone Layer Depletion & PET Granule Production & 77.0 & $\mathrm{~kg}$ CFC-11 eq. \\
\hdashline Depletion of Abiotic Resources -elements, ultimate reserves & Waste Incineration & 50.6 & $\mathrm{~kg}$ antimony eq. \\
\hline
\end{tabular}




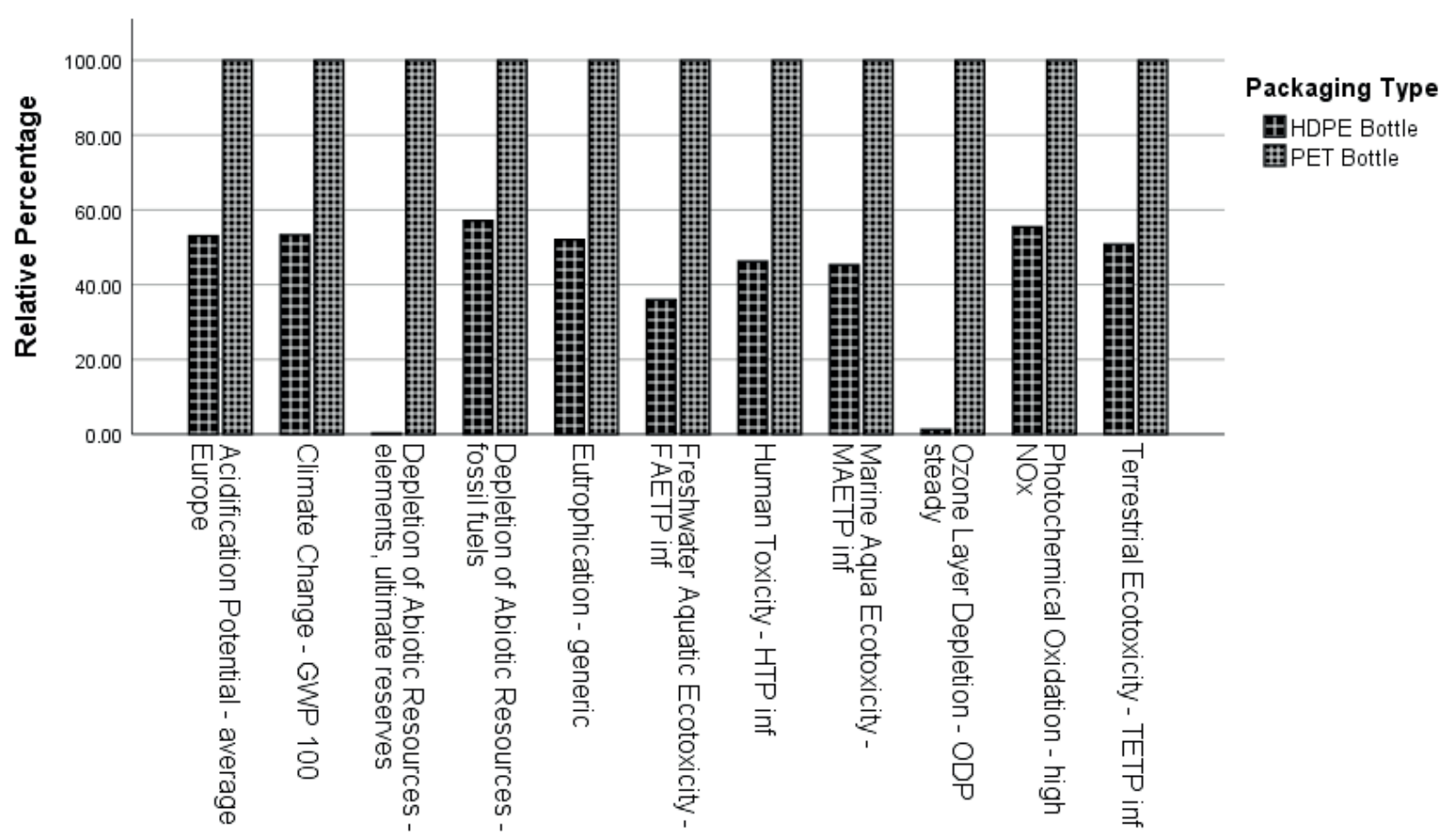

Impact Category

FIGURE 6: Results for HDPE bottle and PET bottle life cycle assessment using CML impact methods. Maximum indicator is set to $100 \%$ and other variants displayed in relation to this result indicating differences from maximum indicator.

\section{DISCUSSION}

\subsection{Key Results}

The results indicate that there are less impactful packaging types than the two modelled plastic bottles, PET and HDPE in all three beverage packaging categories. The replacement packaging types in each category are shown in Table 12.

In each category the glass and recycled glass bottle were always the most impactful packaging type. Both plastics always came below both glass packaging types but above the other modelled packaging types in each category. PET plastics showed maximum impacts in 'Depletion of Abiotic Resources -elements, ultimate reserves' and 'Ozone Layer Depletion' CML impact method categories, indicating there are still considerable costs to using plastics.

Whilst the weights of all the packaging types were fairly consistent, the glass bottles varied greatly in weight with the heaviest weighing $980 \mathrm{~g}$. This variation in weight would likely mean that the bottles at each end of the range would present different impact results (an average was taken for this study). Another factor was that energy had to be carefully allocated. Incorrect energy allocation could lead to certain product systems, such as a milk cartons, having far higher impacts in certain categories. This links back to the earlier discussion on allocation; every effort was made to ensure all data used was suitable for the UK, and if not from a UK source modified for UK energy mixes.

The decision to not use weighting allowed all impact categories to be given equal ranks so level of overall impact was clear to understand. If this study had a specific focus, such as finding packaging with lower water demands then weighting would have been appropriate, but this study sought least impactful overall packaging without contending with the complexities of each impact and the controversy of placing impacts above each other.

In the Pressurised Beverage Packaging category, packaging was chosen that was commonly used for pressurised beverages. PET plastic bottles are the most common packaging in this category (Hahladakis et al., 2018). Pressurised beverage packaging has to be able to withstand pressurisation meaning the Tetra Pak and milk carton types of packaging were unsuitable. It is likely weight was a factor in the results of the assessment, the lightest packaging types, the aluminium can, and recycled aluminium can were the least impactful, although the virgin aluminium can only ranked slightly better than the PET bottle.

This differs from results of other LCAs on PET plastic bottles and aluminium cans. Some have found aluminium to be more impactful than PET plastic, especially when weighting has taken place. Others found aluminium cans to have a far higher climate change (GWP impact) than PET plastics (Amienyo et al., 2013; Franklin Associates, 2009). This may be due to the scoping out of transport as much bauxite is mined in Australia and transport to and from that continent would have high fuel demands (Amienyo et al., 2013). Many LCAs base their measurement on $330 \mathrm{ml}$ aluminium cans whereas we hypothesised one can that would hold 1 litre of the beverage, thus using significantly less material by comparison. The dataset used for the manufacture of the aluminium sheet for the aluminium can sources the majority of the energy used in production from hydropower, which is far less damaging to the climate, where the PET granule manufacture uses a majority of oil, coal and gas energies. 
TABLE 12: Highest contributing processes to PET bottles' product system impacts for CML impact categories in which they had highest impacts. Table does not indicate percentage contributed compared to other product systems in categories.

\begin{tabular}{ll} 
Beverage Packaging Category & $\begin{array}{l}\text { Packaging Types to Replace } \\
\text { Plastics }\end{array}$ \\
\hline Pressurised & $\begin{array}{l}\text { Aluminium can or } 100 \% \text { recycled } \\
\text { aluminium can }\end{array}$ \\
\hline Fruit Juice & Tetra Pak \\
\hline Milk & Milk Carton \\
\hline
\end{tabular}

The fruit juice category showed similar results to the pressurised beverage packaging category. The Tetra Pak's low impacts are due to the fact that around $75 \%$ of the Tetra Pak packaging is made of paper, which unlike the other materials used in beverage packaging, is renewable (Fachverband and Kartonverpackungen, 2007; Jelse et al., 2009).

The Tetra Pak may show low impacts due to the far lower energy demands and the highest proportion of the container being made of paper which does not require mining or other similar processes to extract. However, the recycling of Tetra Pak is problematic, whilst all the component parts can be recycled this is an energy intensive process as the composite material must be separated then the additional recycling processes must take place (TERI, 2010; Tetra Pak, 2012). The plastic and paper materials which make up most of the Tetra Pak are not indefinitely recyclable due to the shortening of the paper fibres and polymer chains, additionally this recycled material is often downcycled into less recyclable products (TERI, 2010).

The impacts on both water ecotoxicity categories for the Tetra Pak, the categories it has the most noticeable impacts on, is from the polythene and aluminium as characterised by openLCA, the paper content of the packaging seems to have little impact on any CML impact category. However if a different impact category set was used that considered water demands it may have greater impacts due to growing trees.

In the Milk Beverage Category both the HDPE bottle and milk carton products showed far lower impacts than both the virgin glass and recycled glass bottles. Both are over fifteen times lighter than the glass bottles modelled so use far less material. Both also require far lower temperatures to be manufactured, the milk carton only using heat for the LDPE plastic coating over the main paper body of the packaging. The milk carton has less environmental impacts than the HDPE bottle in this category as it is made predominantly of paper and is only $5 \%$ plastic.. The results of this study align with the findings of the extensive literature review of by Von Falkenstein et al., (2010), which found most LCAs assigned the lowest impacts to carton type packaging particularly for climate change and acidification potential.

The milk carton has similarly problematic recyclability issues to the Tetra Pak, whilst it does not include aluminium so separation of the composite materials includes less energy, there is still a limited number of councils that collect cartons, and only one UK carton recycling plant (WRAP, 2017). There are similar issues to the Tetra Pak with the materials having limited recyclability and will often be made into downcycled materials and products. Similarly to the Tetra Pak, the milk carton shows most impacts on the marine and freshwater ecotoxicity categories; this is due to the LDPE coating on the packaging. However, as the models do include end of life treatment these packaging types still rank far lower in impacts than other packaging in their categories even with their low recycling rate.

Whilst this study was not conducted using data directly obtained from the manufacturer or using the ecoinvent database, as many of the studies in this area do, instead using and adapting freely available data, similar results have been reached (Amienyo et al., 2013; Cleary, 2013; Eriksson et al., 2009; Meyhoff Fry et al., 2010; Saleh, 2016). This is important to note due to the complexity of LCAs and the general reliance of practitioners on these sources of information. Our results are consistent with the general outcomes from other LCAs obtained using information accessible to those without the means to access expensive or privileged sources of information.

When the PET plastic bottle and the HDPE plastic bottle were compared the HDPE's lower impact scores, and relative lightness compared to the PET suggests light weighting may be a solution to be explored for PET bottles, as reducing the material used will reduce the impact per container. This could be considered for all packaging types; lighter containers are generally less impactful and the heaviest packaging, glass, was always the most impactful overall in all packaging categories.

Other studies have found virgin and recycled glass to have a high level of impacts relative to other packaging (Accorsi et al., 2015; Cleary, 2013; Saleh, 2016). Other studies have also found plastics to have high comparative impacts to ozone depletion and abiotic resource depletion compared to other packaging types, as found in this study (Fachverband and Kartonverpackungen, 2007; Jelse et al., 2009; Meyhoff Fry et al., 2010). The other beverage containers tested showed similar results to previous LCAs that tested their product type, except for aluminium cans showing high Aquatic ecotoxicity in previous studies. Tetra Pak and milk cartons had lower impacts than other beverage containers except those that modelled containers not included in this study, such as pillow pouches for milk; (Fachverband and Kartonverpackungen, 2007; Jelse et al., 2009; Meyhoff Fry et al., 2010; Saleh, 2016). The only assessed beverage packaging type that did not show similar results, as previously discussed, was the aluminium can when compared to the PET bottle.

One of the study's aims was to critically evaluate the costs, benefits, advantages and disadvantages of plastic as a beverage packaging material. The results of the LCA yield some valuable results in this regard. Plastics are less impactful on a single use basis than glass (even $100 \%$ recycled glass), probably because it is considerably lighter and requires less energy to manufacture, so there are benefits from using plastics as packaging materials. The HDPE plastic showed no maximum indicators in any category, showing it could be a lower impact alternative to glass.

When the PET and HDPE bottles were compared, the results for impacts in the 'Depletion of Abiotic Resources -elements, ultimate reserves' and 'Ozone Layer Deple- 
tion' showed how high the impacts from PET bottles are in these categories. HDPE in the Milk Beverage Packaging Category did not show the lowest impacts in those categories. The HDPE bottle is lighter than the PET bottle and the granules require less energy to manufacture (see Appendix 1). The differences in the manufacturing processes of these two polythene-based thermoplastics may factor into the vast comparative difference between their impacts. A higher amount of crude oil is used to manufacture the PET granules than the HDPE granules per kilogram which likely contributes in part to the impact gap between the two (Plastics Europe, 2018).

Unlike the HDPE bottle, the PET bottle showed up as a maximum indicator in some CML impact categories. The categories in which PET was maximum indicator in the pressurised and fruit juice categories ('Depletion of Abiotic Resources -elements, ultimate reserves' and 'Ozone Layer Depletion') are in line with other studies (Accorsi et al., 2015; Morales-Méndez and Silva-Rodríguez, 2018). The biggest factor in both of these impacts is the production of plastic granules, which encompasses inputs and outputs of mining raw materials, processing, and preparation for manufacture. Ozone depletion has been linked to plastic production by several other studies, in some studies this is found to be due to chemicals used in the blowing process, however, this stage is not part of granule production (Morales-Méndez and Silva-Rodríguez, 2018). Therefore, the costs of PET plastics as a beverage packaging are high in these processes as both contribute to the depletion of resources, ultimate reserves and fossil fuels; this is unsustainable.

Plastics are widely recycled, unlike some of the other modelled packaging such as Tetra Pak, and rPET and rHDPE granules are now available to be used in bottle manufacture, however they do not alter the manufacture process which glass cullet does by lowering heat or energy demands (Meyhoff Fry et al., 2010). The only potential reduction in impacts from using recycled plastics granules is in relation to minimising extraction of raw materials and initial material production. However, as plastics are not indefinitely recyclable, raw materials will always need to be extracted to create new bottles.

Plastics have many benefits as a packaging material, being light, durable and less fragile than glass and needing less raw materials per bottle than some of their alternatives (Andrady and Neal, 2009). In some cases, such as bottled water supplied to areas with unsanitary water stress, plastic bottles are vital, and plastics can be used for many beverage types. However as demonstrated in this study plastic bottles can have high environmental impacts compared to some other beverage packaging, and in a few impact categories are worse than the far heavier glass.

Glass bottles, both virgin and recycled had high impacts compared to all other product systems, however this does not consider the potential of reusing the glass bottles. Many communities no longer have milk delivered, but previously this was common across the United Kingdom (Campbell, 1994). These glass bottles were reused multiple times, this is referred to as its trippage rate, for milk bottles this is between 20 and 40 cycles of reuse before the glass would have to be disposed of or recycled (Campbell, 1994). This would imply, roughly, that one glass bottle, when reused would be able to hold the equivalent of between 20 - 40 single use bottles. If this glass were then recycled it could be less impactful per use than the HDPE plastic bottles. The LCA by Mata and Costa, (2001) found that reused glass bottle schemes had far lower impacts in all tested impact categories scoped into that study, than non-returned glass systems. Whilst this study was undertaken under the former ISO standards, it still indicates that reuse of glass would be beneficial, especially when compared to single use glass bottles. This study is also supported by the findings of Simon et al., (2016), which found that if a glass bottle was reused it would reduce the environmental impacts of the container, however reuse only continued to net benefits for between $7-9$ uses where it plateaus and no further significant benefits are generated. Changing to a reuse scheme would entail far more complex logistics, even if door to door delivery were not put into place, potentially a deposit scheme or personal refilling would have to be set up which would be less convenient than door to door delivery.

People could be encouraged to move away from buying beverages that could be made at home. Whilst generally people cannot produce animal milk or fruit juice at home, people can already make pressurised beverages with systems such as SodaStream's sparkling water maker to which flavoured syrups can be added to make at-home versions of popular sparkling drinks (Sodastream, 2019). This makes use of reusable, durable plastic bottles rather than single use beverage packaging. Alongside at-home solutions, common sparkling drinks such as cola, are already frequently provided in fast food restaurants on tap at 'free refill' stations, these could also be utilised 'on the go' by people bringing their own container, much as increasingly more people do with refillable coffee cups (Smithers, 2018). The United Kingdom's government has put forward the idea of a tax on disposable coffee cups which has, for some, been a driving force to switch to reusable alternatives, some coffee outlets also offer discounts for those using reusable cups, or reward schemes (Environmental Audit Committee, 2018; Smithers, 2018). Similar pressure on single use packaging, such as a tax, could also cause changes in behaviour and a move towards reusable beverage containers and refill systems.

Plastics are also considered to be less inert in the environment than glass, as plastics when broken down into smaller microplastics have many well documented detrimental impacts on the environment this study has not been able to entirely capture the complex impacts plastic particles can have (Vethaak and Leslie, 2016; Eriksen et al., 2014). Plastic waste in the environment is noted as a habitat for various bacteria and pathogens that can be detrimental to the environment, whilst there is less research on glass in this context it does not seem to have the same impact potential (Vethaak and Leslie, 2016).

Whilst there would still be packaging involved in the methods outlined above it would be far less, and more renewable solutions could be found for those, for example if a supermarket was providing refills, the containers 
used to transport the concentrate could also be refillable and reusable and taken back by the beverage manufacturer. Companies like Sodastream already have infrastructure in place for gas canisters for their products to be returned and refilled. Refill stations would be arguably more difficult for beverages such as fresh milk and fresh fruit juice that are more prone to spoiling and have a shorter shelf life but could be possible with appropriate management and changes in customer behaviour.

\subsection{Limitations}

LCA sometimes struggles to model the impacts of unpredictable factors. For example, the likelihood of incidents due to extraction processes or dangerous manufacturing processes are complicated to model because they do not occur regularly and cannot be scoped into a LCA. The various different ways materials might be extracted or obtained cannot all be placed into a single model and the potential for endless iterations of the models is difficult to manage. Similarly, the management of waste in ways that are unpredictable (such as upcycling or fly-tipping) can add a level of complexity that LCA cannot account for.

Transport was scoped out of the study due to the complexity and variability of transportation methods; each shipment of beverage packaging may come from different sources depending on the company producing the beverage. Some may have their packaging produced in the same factory others may ship them in from overseas. There is no standard that can be applied. However, this does remove a vital source of emissions from the assessment as vehicular pollutants can be highly impactful on the environment and human health. Alongside this some studies that have attempted to scope in transportation have found that heavier, bulkier packaging types require more fuel and energy to transport, which would likely impact the results of the assessment for this study (Accorsi et al., 2015).

\section{CONCLUSIONS}

This study has successfully reviewed the costs, benefits, advantages and disadvantages of plastics as packaging materials and used LCA to determine if there is less environmentally impactful beverage packaging than plastic bottles. It compares beverage packaging through usage, giving clear results within the scope of the LCA. In each category there are more environmentally-friendly alternatives to plastic bottles. For pressurised beverages, aluminium cans, particularly recycled aluminium cans, are less impactful. For fruit juice, Tetra Pak packaging is less impactful and for milk, cartons are less impactful. However, glass bottles even if they are made completely from recycled materials are more impactful than plastic bottles.

This shows that whilst there are single use beverage packaging replacements for plastics they themselves are not the most negatively impactful single use beverage packaging within the scope of this study.

Whilst this study supports the results of previous LCAs for beverage packaging, we have not used subjective weighting and we have used: i) free, open source software and ii) the comprehensive CML impact categories that al- low for a wider analysis of the overall impacts of all packaging types than many previous studies. Due to datasets being frequently updated for the processes that make up product systems LCAs need to keep current with changes to production especially as new innovations and changes to energy provision can drastically change the environmental impacts of products.

It is recommended that the packaging types identified as the least impactful in each category are used in situations where single use packaging is required. However, there should be a move towards reusable beverage packaging to reduce environmental impacts and encourage more sustainable lifestyles. Changes in infrastructure and potential incentives to use reusable packaging should be implemented and policies such as the proposed coffee cup tax should be adapted for single use beverage packaging. All beverage packaging assessed showed some form of environmental impacts and both the milk carton and Tetra Pak, despite being less impactful than the plastic bottles still contain plastic elements.

\section{REFERENCES}

Accorsi, R., Versari, L., Manzini, R., 2015. Glass vs. plastic: Life cycle assessment of extra-virgin olive oil bottles across global supply chains. Sustain. 7, 2818-2840. https://doi.org/10.3390/ su7032818

Amienyo, D., Gujba, H., Stichnothe, H., Azapagic, A., 2013. Life cycle environmental impacts of carbonated soft drinks. Int. J. Life Cycle Assess. 18, 77-92. https://doi.org/10.1007/s11367-012-0459-y

Andrady, A.L., Neal, M.A., n.d. Applications and societal benefits of plastics. https://doi.org/10.1098/rstb.2008.0304

Andreyeva, T., Long, M.W., Brownell, K.D., 2010. The impact of food prices on consumption: a systematic review of research on the price elasticity of demand for food. Am. J. Public Health 100, 216-22. https://doi.org/10.2105/AJPH.2008.151415

Bare, J.C., Pennington, D.W., Haes, H.A.U. de, 2008. Life cycle impact assessment sophistication. Int. J. Life Cycle Assess. 4, 299-306. https://doi.org/10.1007/bf02979184

Bettens, F., Bagard, R., 2016. Life Cycle Assessment of Container Glass in Europe Methodological report European Container Glass Federation (FEVE). Brussels.

Bjørn, A., Moltesen, A., Laurent, A., Owsianiak, M., Corona, A., Birkved, M., Hauschild, M.Z., 2018a. Life Cycle Inventory Analysis, in: Life Cycle Assessment. Springer International Publishing, Cham, pp. 117-165. https://doi.org/10.1007/978-3-319-56475-3_9

Bjørn, A., Owsianiak, M., Laurent, A., Olsen, S.I., Corona, A., Hauschild, M.Z., 2018b. Scope Definition, in: Life Cycle Assessment. Springer International Publishing, Cham, pp. 75-116. https://doi. org/10.1007/978-3-319-56475-3_8

Bjørn, A., Owsianiak, M., Molin, C., Laurent, A., 2018c. Main Characteristics of LCA, in: Life Cycle Assessment. Springer International Publishing, Cham, pp. 9-16. https://doi.org/10.1007/978-3-31956475-3_2

Campbell, A.J., 1994. The recycling, reuse and disposal of food packaging materials: a UK perspective, in: Food Packaging and Preservation. Springer US, Boston, MA, pp. 210-221. https://doi. org/10.1007/978-1-4615-2173-0_12

Cleary, J., 2013. Life cycle assessments of wine and spirit packaging at the product and the municipal scale: a Toronto, Canada case study. J. Clean. Prod. 44, 143-151. https://doi.org/10.1016/J. JCLEPRO.2013.01.009

Curran, M.A., 2017a. Overview of Goal and Scope Definition in Life Cycle Assessment. pp. 1-62. https://doi.org/10.1007/978-94-0240855-3_1

Curran, M.A. (Ed.), 2017b. Goal and Scope Definition in Life Cycle Assessment, LCA Compendium - The Complete World of Life Cycle Assessment. Springer Netherlands, Dordrecht. https://doi. org/10.1007/978-94-024-0855-3 
Dick Vethaak, A., Leslie, H.A., 2016. Plastic Debris Is a Human Health Issue. https://doi.org/10.1021/acs.est.6b02569

Environmental Audit Committee, 2018. Disposable Packaging: Coffee Cups Second Report of Session 2017-19 Report, together with formal minutes relating to the report.

Environmental Audit Committee, 2017. Plastic bottles: Turning Back the Plastic Tide First Report of Session 2017-19 Report, together with formal minutes relating to the report.

Epstein, L.H., Jankowiak, N., Nederkoorn, C., Raynor, H.A., French, S.A., Finkelstein, E., 2012. Experimental research on the relation between food price changes and food-purchasing patterns: a targeted review. Am. J. Clin. Nutr. 95, 789-809. https://doi.org/10.3945/ ajcn.111.024380

Eriksen, M., Lebreton, L.C.M., Carson, H.S., Thiel, M., Moore, C.J., Borerro, J.C., Galgani, F., Ryan, P.G., Reisser, J., 2014. Plastic Pollution in the World's Oceans: More than 5 Trillion Plastic Pieces Weighing over 250,000 Tons Afloat at Sea. PLoS One 9, e111913. https://doi.org/10.1371/journal.pone.0111913

Eriksson, E., Jelse, K., Einarson, E., Ekvall, T., 2009. Life Cycle Assessment of consumer packaging for liquid food.

Fachverband, Kartonverpackungen, 2007. Life Cycle Assessment: Beverage Cartons Under Test. Wiesbaden.

Franklin Associates, 2009. LIFE CYCLE INVENTORY OF THREE SINGLE-SERVING SOFT DRINK CONTAINERS Revised Peer Reviewed Final Report Prepared for PET Resin Association. Prairie Village.

Hahladakis, J.N., Purnell, P., lacovidou, E., Velis, C.A., Atseyinku, M., 2018. Post-consumer plastic packaging waste in England: Assessing the yield of multiple collection-recycling schemes. Waste Manag. 75, 149-159. https://doi.org/10.1016/J.WASMAN.2018.02.009

Jelse, K., Eriksson, E., Einarson, E., 2009. Life Cycle Assessment of consumer packaging for liquid food LCA of Tetra Pak and alternative packaging on the Nordic market. Stockholm.

Laist, D.W., 1987. Overview of the biological effects of lost and discarded plastic debris in the marine environment. Mar. Pollut. Bull. 18, 319-326. https://doi.org/10.1016/S0025-326X(87)80019-X

Mata, T.M., Costa, C.A. V., 2001. Life cycle assessment of different reuse percentages for glass beer bottles. Int. J. Life Cycle Assess. 6 307-319. https://doi.org/10.1007/BF02978793

Meyhoff Fry, J., Hartlin, B., Wallen, E., Aumonier, S., 2010. Final Report Retail 2010 LCA on milk containers. Oxon.
Morales-Méndez, J.-D., Silva-Rodríguez, R., 2018. Environmental assessment of ozone layer depletion due to the manufacture of plastic bags. Heliyon 4, e01020. https://doi.org/10.1016/j.heliyon.2018.e01020

O'Rourke, D., Connolly, S., 2003. J UST O IL ? T HE D ISTRIBUTION OF E NVIRONMENTAL AND S OCIAL I MPACTS OF O IL P RODUCTION AND C ONSUMPTION. Annu. Rev. Environ. Resour. 28, 587-617. https://doi.org/10.1146/annurev.energy.28.050302.105617

Romero-Hernández, O., Romero Hernández, S., Muñoz, D., Detta-Silveira, E., Palacios-Brun, A., Laguna, A., 2009. Environmental implications and market analysis of soft drink packaging systems in Mexico. A waste management approach. Int. J. Life Cycle Assess. 14, 107-113. https://doi.org/10.1007/s11367-008-0053-5

Rosenbaum, R.K., 2017. Selection of Impact Categories, Category Indicators and Characterization Models in Goal and Scope Definition. pp. 63-122. https://doi.org/10.1007/978-94-024-0855-3_2

Rosenbaum, R.K., Hauschild, M.Z., Boulay, A.-M., Fantke, P., Laurent, A., Núñez, M., Vieira, M., 2018. Life Cycle Impact Assessment, in: Life Cycle Assessment. Springer International Publishing, Cham, pp. 167-270. https://doi.org/10.1007/978-3-319-56475-3_10

Saleh, Y., 2016. Comparative life cycle assessment of beverages packages in Palestine. J. Clean. Prod. 131, 28-42. https://doi. org/10.1016/J.JCLEPRO.2016.05.080

Smithers, R., 2018. UK retailers see rise in sales of reusable coffee cups [WWW Document]. Guard. URL https://www.theguardian. com/environment/2018/jan/11/uk-retailers-see-rise-in-sales-ofreusable-coffee-cups (accessed 4.16.19).

Sodastream, n.d. SodaStream | About SodaStream [WWW Document]. URL https://corp.sodastream.com/about/ (accessed 4.16.19).

TERI, 2010. Tetra Pak Cartons Post Consumer Management.

Tetra Pak, 2012. Protecting the Future: Tetra Pak Environment \&amp; Social Report.

The Ellen McArthur Foundation, 2016. The New Plastics Economy.

Von Falkenstein, E., Wellenreuther, F., Detzel, A., 2010. LCA studies comparing beverage cartons and alternative packaging: Can overall conclusions be drawn? Int. J. Life Cycle Assess. 15, 938-945. https://doi.org/10.1007/s11367-010-0218-x

WRAP, 2017. Collection of food and drink cartons at the kerbside Guidance for local authorities and waste contractors. 